\title{
Beakdugu-tang, Traditional Korean Digestant Medicine, Inhibits Hepatic Steatosis in Insulin Resistance Cell Model with HepG2 and THP-1
}

\author{
Hyuck Kim${ }^{1}$, Dong-Woo Lim², Sung Yun Park ${ }^{1}$, Sun-Dong Park ${ }^{3}$, Won-Hwan Park ${ }^{1}$, \\ Jai-Eun $\mathrm{Kim}^{2}$ \\ ${ }^{1}$ Department of Diagnostics, College of Korean Medicine, Dongguk University, Goyang \\ ${ }^{2}$ Department of Pathology, College of Korean Medicine, Dongguk University, Goyang \\ ${ }^{3}$ Department of Prescription, College of Korean Medicine, Dongguk University, Goyang
}

\begin{abstract}
Objectives: Beakdugu-tang (BDGT) consists of three medicinal herbs, and this prescription has long been used in treatment of various digestant problem in Korea. In this study, we designed to clarify mechanisms by which Korean traditional digestive medicine, BDGT, may exert anti-hepatic steatosis effects via improved insulin resistance cell model in human hepatocellular carcinoma (HepG2) and monocyte (THP-1).

Materials and methods: The preparation of BDGT and constituents were extracted with $70 \%$ ethanol. HepG2 and THP-1 were treated with different concentrations of BDGT and constituents in the presence and absence of stimulants such as free fatty acids (FFAs) and oxidized low-density lipoprotein (ox-LDL), respectively.

Results: The BDGT and its constituents inhibited the FFAs-stimulated lipid accumulation in HepG2 cells. Ethanol extracts of Amoтит cardamomum (ACE) improved the ox-LDL induced insulin resistance in THP-1 cells. Also, treatment of monocytic cells with ACE increased anti-hepatic steatosis related gene levels including ABCA, ABCG and SR-B1.

Conclusion: The results suggest that the ethanol extract of BDGT and its constituents potently inhibit the FFAs- and ox-LDL induced liver steatosis via improved insulin resistance.
\end{abstract}

$\overline{\text { Key Words }}$ : Beakdugu-tang, hepatic steatosis, insulin resistance, digestant medicine

\section{Introduction}

Hepatic steatosis, considered the first step in the pathophysiologic continuum of non-alcoholic fatty liver disease (NAFLD), remains as a major global health problems ${ }^{1)}$. NAFLD, is one of the types of fatty liver which occurs when fat is deposited in the liver, is also closely related with type 2 diabetes mellitus ${ }^{2,3)}$. Type 2 diabetes mellitus is a metabolic disease characterized by insulin resistance (IR) and high blood glucose level ${ }^{4,5)}$. Metformin, the first choice treatment for the type 2 diabetes, is known to suppress gluconeogenesis across various conditions of diabetes such as prediabetes and gestational diabetes $^{6-8)}$. However, metformin has relatively well known common side effects including diarrhea, nausea and abdominal pain. The mechanisms of these side effects of modern synthetic drugs used to

\footnotetext{
- Received : 26 May 2017

- Revised : 21 June 2017

- Accepted : 21 June 2017

- Correspondence to : Jai-Eun Kim

Department of Pathology, College of Korean Medicine, Dongguk University

Dongguk-Ro 32, Goyang, Gyeonggi-Do, 10326, Republic of Korea

Tel : +82-31-961-5829, Fax : +82-31-961-5835, E-mail : herbqueen@dongguk.ac.kr
} 
treat hepatic steatosis remain unclear. Recently, traditional medicines and plant-derived drugs might be synergetic effects on the treatment of type 2 diabetes $^{9,10)}$.

Beakdugu-tang, a traditional herbal prescription used for treatment of digestive disorders including coldness vomiting, consists of three medicinal herbs, Ammomum cardamomum, Amomum xanthoides, and Pinellia ternate. In vitro and in vivo studies have demonstrates that Amomum cardamomum protects against carbon tetrachloride-induced liver injury in our previously report ${ }^{11}$. Currently, circulating bile acids have been reported in patients related NAFLD $^{12)}$. For these reasons, traditional digestant have been used as an alternative to treat diverse human metabolic disorders and to maintain healthy conditions. This requires the discovery and development of products from traditional sources that may provide complementary and alternative interventions to recently approved medicinal herbs ${ }^{13,14)}$.

In this research, we prepared ethanol extracted Beakdugu-tang (BDGT) and constitutional herbs with the aim of improving its insulin resistance. Using a FFAs-induced human hepatocellular carcinoma and ox-LDL stimulated human monocytes with advanced molecular tools for lipid accumulation and gene expression. Our results indicate that BDGT and its constituents inhibit hepatic steatosis by decreasing intracellular TG in HepG2 and recover insulin sensitivity-related gene levels in THP-1.

\section{Materials and methods}

\section{Cell Culture}

HepG2, human hepatocellular carcinoma cell, was provided by Korean Cell Line Bank (KCLB, Seoul, Korea), and cultured in DMEM (Gibco, USA) with $10 \%$ fetal bovine serum (FBS, Gibco) and $1 \%$ penicillin-streptomycin (Gibco). Human monocytic cell, THP-1 was also obtained from KCLB, and cultured in RPMI-1640 (Welgene, Korea) with 10\% FBS and $1 \%$ antibiotics. Cells were incubated at $37^{\circ} \mathrm{C}$ in a humidified chamber contacting $5 \% \mathrm{CO}_{2}$. For all experiments, early passage cells were maintained and subcultured at $70 \sim 80 \%$ confluence and made quiescent by starvation for at least $24 \mathrm{~h}$.

\section{Preparation of $70 \%$ Ethanol Extract}

BDGT and its three constituent herbs, Ammomom cardamomum (ACE), Amomum xanthoides (AXE), and Pinellia ternate (PTE) were purchased from Human Herb (Gyongsan, Korea). Ethanol extract of BDGT was prepared by mixing BDGT constituent herbs with 1:1:1 ratio, and respective materials also were extracted with $70 \%$ ethanol. All extracts were stirred at room temperature for three days, and then ethanol residue were evaporated using rotary evaporator at $50^{\circ} \mathrm{C}$. Powder form samples were obtained by Labconco freezed-dry system (MO, USA). The yields of BDGT, ACE, AXE and PTE were $6.39 \%, 8.24 \%, 14.49 \%$ and $2.05 \%$, respectively.

\section{Cell Viability Assay}

HepG2 cells seeded at a density of $1 \times 10^{5}$ cells/well in 96 well culture plates. The cells were then incubated with different concentrations of samples in DMEM for $24 \mathrm{~h}$. THP-1, another cells for this experiment, were primed with $100 \mathrm{nM}$ PMA for $24 \mathrm{~h}$ at a density of $5 \times 10^{5}$ cells/well in 96 well plates. The cell viability was determined using the EZ-Cytox cell viability assay Kit (Daeil Lab. Service, Seoul, Korea) as described by the manufacture. Briefly, $10 \mu \mathrm{l}$ of the EZ-Cytox reagent was added to each culture well and incubated at $37^{\circ} \mathrm{C}$ in the $\mathrm{CO}_{2}$ incubator for $2 \mathrm{~h}$. After incubation, the viability of cells was measured at a wavelength of $450 \mathrm{~nm}$ using a microplate reader (VersaMax, Molecular Devices, USA). 


\section{Determination of Intracellular Triglycerides (TG)}

For experimental purpose, HepG2 cells were seeded at a density of $1 \times 10^{5}$ cells/well in 24 well plates. After $24 \mathrm{~h}$ incubation, the supernatant was discarded and replaced with fresh DMEM containing $1 \%$ bovine serum albumin (BSA). Hepatic steatosis conditions were induced by treating the cells in plates for another $24 \mathrm{~h}$ with a mixture of free fatty acids (FFAs, oleic acid : palmitic acid, 2:1, w/w). HepG2 cells were washed with ice-cold phosphate -buffered saline (PBS), scraped and transferred into tubes and then centrifuged at 3,000 rpm for $5 \mathrm{~min}$. Intracellular triglycerides (TG) was measured using a Triglyceride assay kit (Asan pharmacology, Seoul, Korea) as described by the manufacture.

\section{Lipid Accumulation Test (Oil Red O assay)}

For this experiment, HepG2 cells were seeded at a density of $5 \times 10^{5}$ cells/well in 6 well plates. After the completion of desired treatment schedule, cells were washed with PBS and then fixed using 10\% formalin solution for $5 \mathrm{~min}$ at room temperature. After fixation, cells were washed with $60 \%$ isopropanol and then stained with the working solution of Oil Red $\mathrm{O}$ in $60 \%$ isopropanol for 15 min. Result images were obtained by an inverted microscope (Olympus, CKX41, Japan), and the resultant solutions were measured at $520 \mathrm{~nm}$ using microplate reader.

\section{Quantitative Real-time Polymerase Chain Reaction (qPCR)}

For qPCR purpose, THP-1 cells were seeded at a density of $5 \times 10^{5}$ cells $/ \mathrm{ml}$ in $100 \mathrm{~mm}$ culture plates. After the completion of desired treatment schedule, total RNA was isolated from THP-1 cells using TRIZOL reagent (Invitrogen, USA) according to manufacturer's instructions. For reverse transcription, a cDNA was synthesized from $1 \mu \mathrm{g}$ of RNA using AccuPower RT PreMix kit (Bioneer, Korea) according to manufacturer's protocol. The cDNA was amplified by PCR with the following primers: ABCA, 5'-AACAGTTTGTGGCCCTTTTG-3' (sense) and 5'-AGTTCCAGGCTGGGGTACTT-3'(antisense); ABCG, 5'-GGTTCTTCGTCAGCTTCGAC-3' (sense) and 5'-GTTTCCTGGCATTCAGGTGT-3' (antisense); SR-B1, 5'-CTGTGGGTGAGATCAGGTGT-3' (sense) and 5'-GCCAGAAGTCAACCTTGCTC-3' (antosense); GAPDH, 5'-GGCCTCCAAGGAGTAAGACC-3' (sense) and 5'-AGGGGTCTACATGGCACCTG-3' (antisense). PCR amplification comprised $10 \mathrm{~min}$ at $95^{\circ} \mathrm{C}$ for 10 $\mathrm{s}$, annealing at $52^{\circ} \mathrm{C}$ for $30 \mathrm{~s}$, and extension at $72^{\circ} \mathrm{C}$ for 15 s. Results were analyzed using Light Cycler software (Roche Applied Science, Switzerland).

\section{Determination of Glucose Uptake}

In ox-LDL induced insulin resistance THP-1 cells model, glucose uptake was measured by 2(N-(7-nirobenz-2-oxa1,3-diazol-4-yl)amino)-2-deoxygl ucose (2-NBDG, Invitrogen) according to manufacturer's protocol. Cells were seeded on bottom clearly black well plate and then $50 \mu \mathrm{g} / \mathrm{ml}$ of ox-LDL exposure in each well plate. After the completion of desired treatment schedule, fluorescent images were obtained by a fluorescent microscope (Olympus, IX73), and the resultant solution were measured at excitation $485 \mathrm{~nm}$, emission $535 \mathrm{~nm}$ using fluorescent microplate reader (Gemini EM, Molecular Devices).

\section{Statistical Analyses}

The results are expressed as mean \pm standard deviation (SD), and all experimental data were analyzed by Tukey's Multiple Comparison Test using One-Way Anova on the Graph Pad prism 5.0 software (CA, USA). A p-value $<0.05$ was considered statistically significant. 


\section{Results and discussion}

In the present study, the inhibitory effect of BDGT and ACE on FFAs-induced hepatic steatosis or ox-LDL stimulated insulin resistance in vitro model, including HepG2 and THP-1 cell lines are investigated. BDGT is a traditional herbal prescription used for treatment of digestant, and its major medicinal herb is Amomoum cardamomum L., a member of Zingiberaceae, which are used as a spice in many countries and traditionally as a therapeutic for relief of dyspepsia, hiccupping, vomiting, and alcohol detoxification ${ }^{15)}$.

As the results, there was no significant toxicity shown by BDGT treatment to HepG2 cell for $24 \mathrm{~h}$ under $25 \mu \mathrm{g} / \mathrm{ml}$ concentrations. Among the ethanol extracted, ACE displayed the HepG2 cell viability for $24 \mathrm{~h}$ under $50 \mu \mathrm{g} / \mathrm{ml}$ concentrations by $84 \%$ (Fig. 1A). Co-treatment of HepG2 with BDGT and its constituents resulted in markedly inhibited FFA-induced production of intracellular TG. Furthermore, exposure of FFAs-induced cells to ACE pretreatment (10 and $50 \mu \mathrm{g} / \mathrm{ml}$ ) significantly decreased TG levels of lipid accumulation in a dose-dependent manner (1.05 and 0.98, respectively) (Fig. 1B). Several reports showed a decrease in the TG in the intracellular level of TG by the traditional medicines ${ }^{16,17)}$. To investigate the effect of BDGT and ACE treatment on lipid accumulation, HepG2 cells exhibited typical morphological features of lipid staining in a dose dependent manner (Fig. 2A). In Both concentrations of ACE ameliorated hepatic lipid accumulation induced by FFAs. The ORO stain strongly appeared in lesser portion of HepG2 cells in ACE $50 \mu \mathrm{g} / \mathrm{ml}$ compared with FFAs exposure group (Fig. 2B). These results indicate that hyperlipidemia is closely related to the onset and development of hepatic steatosis.

Next, a qPCR assay was used to further characterize the insulin resistance-related genes expression observed.

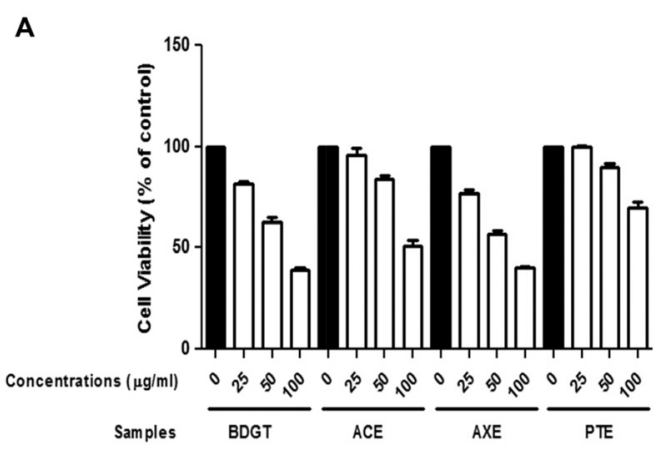

B

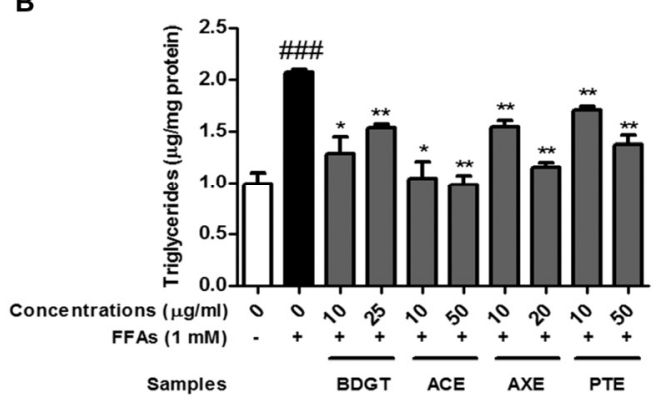

Fig. 1. The effect of Beakdugu-tang and the three constitutional herbs extract on cell viability (A) and FFAs-induced intracellular triglyceride levels (B) in HepG2 cells. Cell viability and intracellular triglycerides were determined using the cell viability and triglyceride detection kits, respectively. All data represent the means $\pm S D$ of three different experiments. Asterisk indicates statistically significant difference between FFAs-induced group $\left.{ }^{*}<0.05,{ }^{* *}<0.01\right)$.

Pravastatin, used as positive control in this study, is a member of the drug class of statins, treated in combination with diet and exercise for lowering cholesterol $^{18,19)}$. ACE alone had no cytotoxicity on THP-1 cell viability at $10 \mu \mathrm{g} / \mathrm{ml}$ concentration by $103.7 \%$ (Fig. 3A). In agreement with this, we found that exposure of THP-1 cells to oxidized LDL at 50 $\mu \mathrm{g} / \mathrm{ml}$ resulted in potently down-regulated intracellular gene levels including $\mathrm{ABCA}, \mathrm{ABCG}$ and SR-B1 (1.15 fold, 0.34 fold and 0.47 fold to control, respectively) (Fig. 3B, C, and D). Besides, pravastatin $(20 \mu \mathrm{M})$ treatment successfully increased insulin resistance-related genes. In previous studies, 

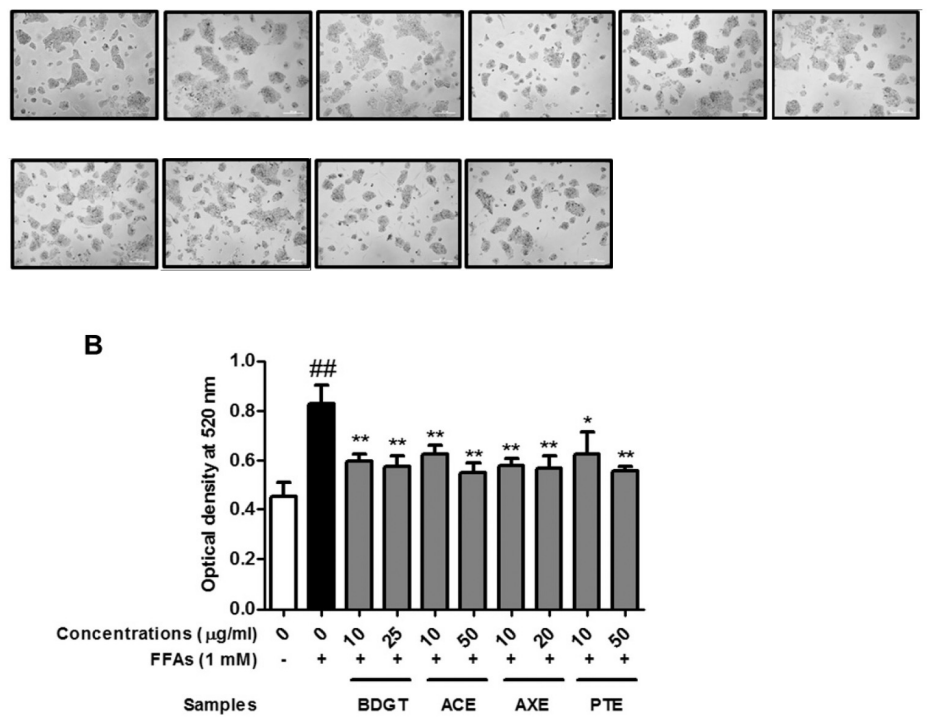

Fig. 2. The effect of Beakdugu-tang and the three constitutional herbs extract on FFAs-stimulated lipid accumulation. (A), Microscopic images and (B), resultant solutions were measured at $520 \mathrm{~nm}$. All data represent the means $\pm S D$ of three different experiments. Asterisk indicates statistically significant difference between FFAs-induced group $\left.{ }^{*}<0.05,{ }^{* *}<0.01\right)$.

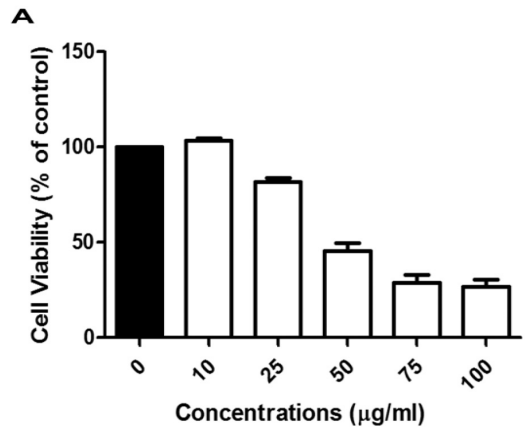

C

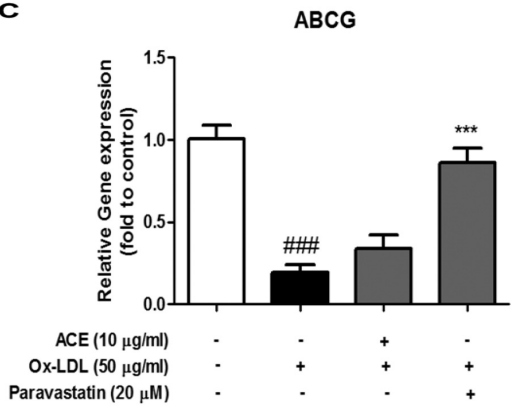

B

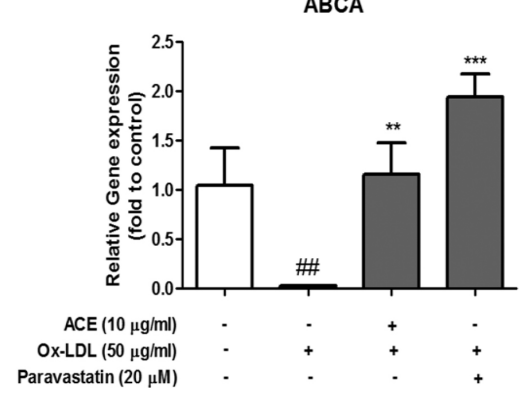

$\mathbf{D}$

SR-B1

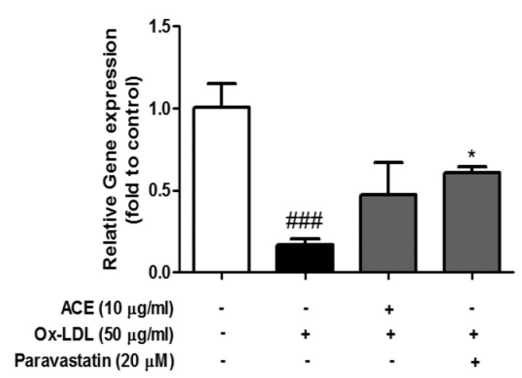

Fig. 3. The effects of Amomum cardamomum ethanol extract on THP-1 cell viability (A) and insulin resistance-related genes expression $(B \sim D)$. All data represent the means $\pm S D$ of three different experiments. Asterisk indicates statistically significant difference between ox-LDL-stimulated group $\left(*<0.05,{ }^{* *}<0.01,{ }^{* * *}<0.005\right)$. 

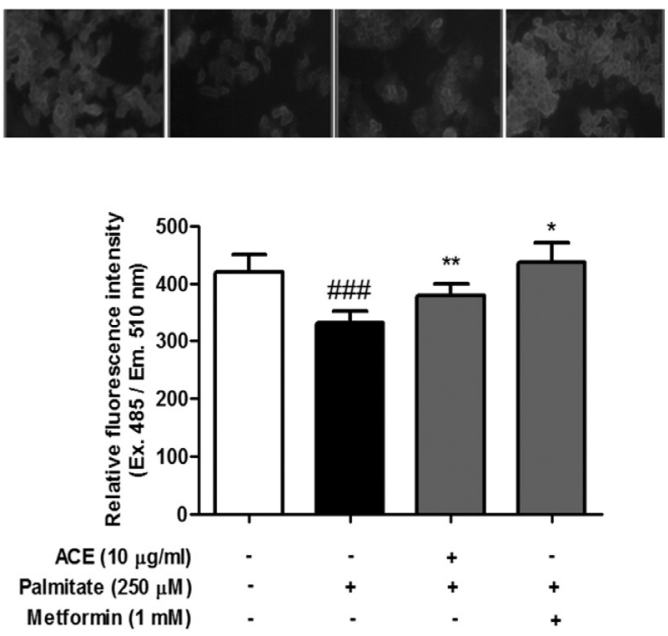

Fig. 4. The effects of Amomum cardamomum ethanol extract on $\mathrm{ox}-\mathrm{-DL}-$ stimulated glucose uptake. (A), Fluorescence microscopic images and $(B)$, resultant were measured at excitation $485 \mathrm{~nm}$, emission $535 \mathrm{~nm}$. All data represent the means $\pm S D$ of three different experiments. Asterisk indicates statistically significant difference between ox- $-D L-$ stimulated group $\left(*<0.05,{ }^{* *}<0.01\right)$.

insulin-resistance has been closely associated with numerous human diseases, such as type 2 diabetes, NAFLD, NASH and cardiovascular damage ${ }^{20-22)}$. The present results show that exposure to oxidized LDL caused significant decrease in ABCA, ABCG, and SR-B1 mRNA levels due to insulin-resistance in THP-1 cells. However, pretreatment of ACE $(10 \mu \mathrm{g} / \mathrm{ml})$ markedly recovered insulin-resistance related-genes, which might be due to the phenolic compounds.

Finally, we demonstrate that ACE alleviated the palmitic acid-induced glucose uptake (Fig. 4A, B). The glucose uptake rate was significantly improved in free fatty acid-induced THP-1 cells at all measurement in response to the pre-treatment with both ACE $(10 \mu \mathrm{g} / \mathrm{ml})$ and metformin $(1 \mathrm{mM})$.

\section{Conclusion}

The present study demonstrates for the first time the anti-hepatic steatosis effect of Korean traditional digestant improved insulin resistance. BDGT treatment alleviated lipid accumulation through down-regulated intracellular TG levels. Especially ACE, well known BDGT constituent, also significantly decreased intracellular TG on FFAs-induced hepatic steatosis in vitro model. ACE also recovered insulin resistant -related genes expression on ox-LDL stimulated THP-1 cells. In addition, ACE alleviated the palmitic acid-induced glucose uptake. These finding suggest that BDGT and ethanol extract of Amomum cardamoum could be therapeutic as a tradition herbal remedy in hepatic steatosis through improved insulin resistance.

\section{Acknowledgement}

This research was supported by Korean Medicine Planning Program through the Dongguk University Research Fund of 2016.

\section{Competing Interests}

The authors declare that they have no competing interests.

\section{References}

1. Richard J, Lingvay I. Hepatic steatosis and type 2 diabetes: current and future treatment considerations. Expert Rev Cardiovasc Ther. 2011;9(3):321-8.

2. Firneisz G. Non-alcoholic fatty liver disease and type 2 diabetes mellitus: the liver disease of our age?. World J Gastroenterol. 2014;20(27):9072-89.

3. Lee DH, Han JM, Yang WM. The effects of Atractylodes japonica Koidz. on type 2 diabetic rats. J Korean Med. 2015;35(1):75-85.

4. Weyer C, Funahashi T, Tanaka S, Hotta K, Matsuzawa Y, Prattey RE, et al. Hypoadiponectinemia in obesity and type 2 diabetes: close association with insulin resistance and hyperinsulinemia. J Clin Endocrinol Metab. 
2001;86(5):1930-5.

5. Kumashiro N, Erion DM, Zhang D, Kahn M, Beddow SA, Chu X, et al. Cellular mechanism of insulin resistance in nonalcoholic fatty liver disease. Proc Natl Acad Sci USA. 2011;108(39): 16381-5.

6. Hundal RS, Krssak M, Dufour S, Laurent D, Lebon V, Chandramouli V, et al. Mechanism by which metformin reduces glucose production in type 2 diabetes. Diabetes. 2000;49(12):2063-9.

7. Mitchell PL, Nachbar R, Lachance D, St-Pierre $\mathrm{P}$, Trottier J, Barbier O, et al. Treatment with a novel agent combining docosahexaenoate and metformin increase protectin DX and IL-6 production in skeletal muscle and reduces insulin resistance in obese diabetic $\mathrm{db} / \mathrm{db}$ mice. Diabetes Obes Metab. 2017;19(3):313-9.

8. Diamanti-Kandarakis E, Kouli C, Tsianateli T, Bergiele A. Therapeutic effects of metformin on insulin resistance and hyperandrogenism in polycystic ovary syndrome. Eur J Endocrinol. 1998;138(3):269-74.

9. Kwon OJ, Lee SW, Paik SH, Han SR, Ahn YM, Ahn SY, et al. The effects of Platycodi radix on obese type 2 diabetes mouse model induced by high fat, high carbohydrate diet. J Korean Med. 2013;34(1):1-14.

10. Lim DW, Bose S, Wang JH, Choi HS, Kim YM, Chin YW, et al. Modified SJH alleviates FFAs-induced hepatic steatosis through leptin signaling pathways. Sci Rep. 2017;30(7):45425.

11. Lim DW, Kim H, Park JY, Kim JE, Moon JY, Park SD, et al. Amomum cardamomum L. ethyl acetate fraction protects against carbon tetrachloride -induced liver injury via an antioxidant mechanism in rats. BMC Complement Altern Med. 2016;16:155.

12. Kobayashi Y, Hara N, Sugimoto R, Mifuji -Moroka R, Tanaka H, Eguchi A, et al. The associations between circulating bile acids and the muscle volume in patients with non-alcoholic fatty liver disease (NAFLD). Intern Med. 2017; 56(7):755-62.

13. Lee KP, Kim JE, Kim H, Chang HR, Lee DW, Park WH. Bo-Gan-Whan regulates proliferation and migration of vascular smooth muscle cells. BMC Complement Altern Med. 2016;16:306.

14. Um ES, Kim YC. Effect of samhwangsasim-tang and daehwanghwangryunsasim-tang on palmitate -induced lipogenesis in HepG2 cells. J Korean Med. 2016;37(1):62-76.

15. Heo J. Translated Dongeuibogam. 1st ed. Seoul: Bubinmunwha. 1999.

16. Ulla A, Alam MA, Sikder B, Sumi FA, Rahman MM, Habib ZF, et al. Supplementation of Syzygium cumini seed powder prevented obesity, glucose intolerance, hyperlipidemia and oxidative stress in high carbohydrate high fat diet induced obese rats. BMC Complement Altern Med. 2017; 17:289

17. Huang Q, Wang T, Yang L, Wang HY. Gisenosied $\mathrm{Rb} 2$ alleviates hepatic lipid accumulation by resorting autophagy via induction of Sirt1 and activation of AMPK. Int J Mol Sci. 2017; 19(18):E1063.

18. Zhang M, Liu C, Hu MY, Zhang J, Xu P, Li F, et al. High-fat diet enhanced retinal dehydrogenase activity, but suppressed retinol dehydrogenase activity in liver of rats. J Pharmacol Sci. 2015;127(4):430-438.

19. Gotoh K, Masaki T, Chiba S, Ando H, Fujiwara $\mathrm{K}$, Shimasaki $\mathrm{T}$, et al. Effects of hydrophilic statins on renal tubular lipid accumulation in diet-induced obese mice. Obes Res Clin Pract. 2013;7(5):e342-352.

20. Bonora E, Targher G. Increase risk of cardiovascular disease and chronic kidney disease in NAFLD. Nat Rev Gastroenterol Hepatol. 2012;9(7):372-381.

21. Masarone M, Rosato V, Aglitti A, Bucci T, Caruso R, Salvatore T, et al. Liver biopsy in type 2 diabetes mellitus: Steatohepatitis represents 
(194) Journal of Korean Medicine 2017;38(2)

the sole feature of liver damage. PLOS One. 2017;12(6):e0178473.

22. Bastard JP, Maachi M, Lagath C, Kim MJ, Caron M, Vidal H, et al. Recent advances in the relationship between obesity, inflammation, and insulin resistance. Eur Cytokine Netw. 2006; 17(1):4-12. 